\title{
Labor Market Participation Before and After Long-Term \\ Part-Time Sickness Absence in Finland A Population-Based Cohort Study
}

\section{Ervasti, Jenni}

2020-04

Ervasti , J , Kausto , J , Koskinen , A, Pentti , J , Vahtera , J , Joensuu , M , Turunen , J , Oksanen , T \& Kivimäki , M 2020 , ' Labor Market Participation Before and After Long-Term Part-Time Sickness Absence in Finland A Population-Based Cohort Study ', Journal of Occupational and Environmental Medicine , vol. 62 , no. 4 , pp. E142-E148 . https://doi.org/10.1097/JOM.000000000

http://hdl.handle.net/10138/328624

https://doi.org/10.1097/JOM.0000000000001818

acceptedVersion

Downloaded from Helda, University of Helsinki institutional repository.

This is an electronic reprint of the original article.

This reprint may differ from the original in pagination and typographic detail.

Please cite the original version. 


\section{Labour market participation before and after long-term part-time sickness absence in Finland: a population-based cohort study}

Jenni Ervasti ${ }^{1,2}$, Johanna Kausto ${ }^{1}$, Aki Koskinen ${ }^{1}$, Jaana Pentti ${ }^{3,4}$, Jussi Vahtera, ${ }^{3}$ Matti Joensuu ${ }^{1}$, Jarno Turunen ${ }^{1}$, Tuula Oksanen ${ }^{1}$, Mika Kivimäki ${ }^{1,4,5}$

1 Finnish Institute of Occupational Health, Helsinki, Finland

2 Institute of Environmental Medicine, Karolinska Institutet, Stockholm, Sweden

3 Department of Public Health, University of Turku, and Population Research Centre, University of Turku and Turku University Hospital, Turku, Finland

4 Clinicum, Faculty of Medicine, University of Helsinki, Helsinki, Finland

5 Department of Epidemiology and Public Health, University College London, London, UK

Correspondence: Dr Jenni Ervasti, Finnish Institute of Occupational Health, PB 18, FI-00032 TYÖTERVEYSLAITOS, Helsinki, Finland, Tel. +358 30474 2806, Email: jenni.ervasti@ttl.fi

Author contributions: JE is the principal investigator, conducted the analyses, and drafted the paper. $\mathrm{JE}, \mathrm{MK}$, and JP planned the study design. JE, JP and AK participated in data management and planning the statistical analyses. All authors (JE, JK, AK, JP, JV, MJ, JT, TO, MK) provided critical interpretation of the data and revised the manuscript. All authors have approved the submitted version and agree to be accountable for all aspects of the work. 
Funding: The study was funded by the Finnish Work Environment Fund (\#118066). MK was supported by the Academy of Finland (311492), Helsinki Institute of Life Science and NordForsk.

Conflict of interest: The authors declare that they have no conflict of interest.

Data availability: The data are property of the register keepers and cannot be publicly shared due to legislative restrictions. Register data can be applied from the Finnish Centre for Pensions:

https://www.etk.fi/tutkimus-tilastot-ennusteet/tutkimus/tutkimusyhteistyo/tutkimusaineistot/and from Statistics Finland: info@tilastokeskus.fi, tutkijapalvelut@tilastokeskus.fi.

Informed consent: This was a register study. Individual consent was not necessary.

Ethical approval: Ethical approval was from the Ethical committee of the Finnish Institute of Occupational Health (3/2017).

Running title: Part-time sickness absence and work participation

Word count (excluding title page, abstract, references, figures and tables): 3418 


\section{ABSTRACT}

Objective: To examine trends in labour market participation among those with long-term part-time or long-term full-time sickness absence.

Methods: Finnish population-based cohort study including 3406 individuals with $>30$-day part-time sickness absence in 2011 and 42,944 individuals with >30-day full-time sickness absence in 2011.

Results: Compared to previous years, the rates of sickness absence and vocational rehabilitation increased after 2011 in both groups. Sickness absence rate was higher in 2012 in the full-time sickness absence group than in the part-time sickness absence group. An increasing trend in unemployment after 2011 was observed in both groups, but the absolute level of unemployment was higher in the full-time sickness absence group.

Conclusion: Long-term part-time sickness absence seems to mark a decline in labour market participation, but the decline is smaller than that in employees with full-time sickness absence.

Keywords: Labour market participation; Partial work ability; Part-time sickness absence; Unemployment; Vocational rehabilitation 


\section{INTRODUCTION}

The World Health Organization estimates that $10 \%$ of the world's population has a disability. ${ }^{1}$ This totals nearly 390 million people of working age with somatic or mental disability, or illness acquired in childhood or later in life, which restricts a person's work or daily activities. ${ }^{1}$ The majority of people with a disability have some working capacity left, often also a desire to work, but studies suggest they are more often unemployed or otherwise outside the labour market than nondisabled individuals. ${ }^{1-4}$ A comprehensive inclusion of people with partial work disability to the labour force is seen as important to ensure sustainable economic wellbeing in ageing societies throughout the world.

One solution to support return to work after sickness absence among people with reduced work ability is part-time work. To compensate the lower income of part-time compared to full-time work, part-time work disability benefits are used in the Nordic countries, and in some other European countries. ${ }^{5}$ In the UK, a somewhat similar practise is called the Fit Note. ${ }^{6}$ According to a population-based study from Finland, $80 \%$ of those with an episode of part-time sickness absence (PTSA) were originally in long-term full-time sickness absence (FTSA). The mode length of preceding FTSA was 49-59 days, ${ }^{7}$ suggesting that PTSA was used to support return to work after long-term work disability. Other studies are consistent with this notion. ${ }^{7-11}$ It has been suggested that PTSA might result in improved work participation, faster return to work, and decreased probability of disability pension as compared to FTSA ${ }^{7-16}$ However, few studies have examined the trends of sickness absence and other labour market outcomes before and after PTSA.

Accordingly, the aim of the current study was to examine trends in three labour market outcomes, annual sickness absence days, participation in vocational rehabilitation and unemployment, four years before and four years after the first long-term (>30 days) PTSA, and to 
compare changes in labour market outcomes between PTSA group and those with the first longterm FTSA.

\section{METHODS}

\section{Study context}

PTSA benefit was introduced in Finland in 2007 and is offered by the Social Insurance Institution of Finland to employed individuals who can work for $40-60 \%$ of contracted full working time. From 2010 onwards, part-time sickness benefit has been available after a 10-day waiting period (this is also the case for FTSA) or without a waiting period if it follows immediately after the payment of FTSA or vocational rehabilitation allowance. The maximum duration of PTSA is 120 working days. After this has been reached, the employee can be compensated for PTSA from the same illness only if (s)he has in the meantime been able to work for at least one year. ${ }^{17}$ There is no waiting period for FTSA after PTSA. FTSA can be granted for a maximum of one year.

\section{Study population}

The participants were from a nationwide research database 'State of the Labour Force in Finland', which includes a 90\% random sample of all Finnish residents aged 18-68 years in 2010-2015 (total $N>3,500,000$ ). For this study, we obtained linked records of earnings, pensions, and a variety of other social security benefits from the Finnish Centre for Pensions until December 31, 2015. In addition, the participants have been linked to data from Statistics Finland regarding their 
sociodemographic characteristics and mortality. The linkage of several register databases was performed using personal identification numbers assigned to each citizen of Finland. All register data from the register keepers were forwarded to Statistics Finland where personal identification numbers were replaced by pseudo-identifiers precluding identification of individuals. We analysed the pseudonymized data through the Finnish Online Access portal 'Fiona' provided by Statistics Finland.$^{18}$ The study was approved by the ethical committee of the Finnish Institute of Occupational Health.

We created two study groups. As PTSA benefits are not granted for the unemployed, we excluded persons who were unemployed during 2011 from both study groups. The first group included all individuals who had been granted a PTSA benefit of more than 30 days in 2011, and who had no record of PTSA benefits during 2007-2010, and no unemployment days in 2011 ( $n=3600$ ). The second group consisted of all individuals who had been granted a FTSA benefit lasting at least 30 days in 2011, who had no record of PTSA benefits during 2007-2010, and no unemployment days in $2011(n=57803)$.

We used on a 9-year observation window: from 4 years before the index event (i.e., the sickness absence year) to 4 years after. We excluded persons who had missing information on covariates, persons who were granted any kind of pension prior to 1.1.2012, and those who died during 2011. This resulted in 3406 individuals with the first >30-day episode of PTSA in 2011 and 42 944 individuals with a >30-day episode of FTSA in that year (Figure 1). Those who died, were granted full-time disability pension, old-age or other full-time pension during the follow-up from 2012 to 2015 were excluded from the analyses from the year of death or pension (whichever was first) onwards, totalling 14800 participants (32\%) until the end of follow-up. 


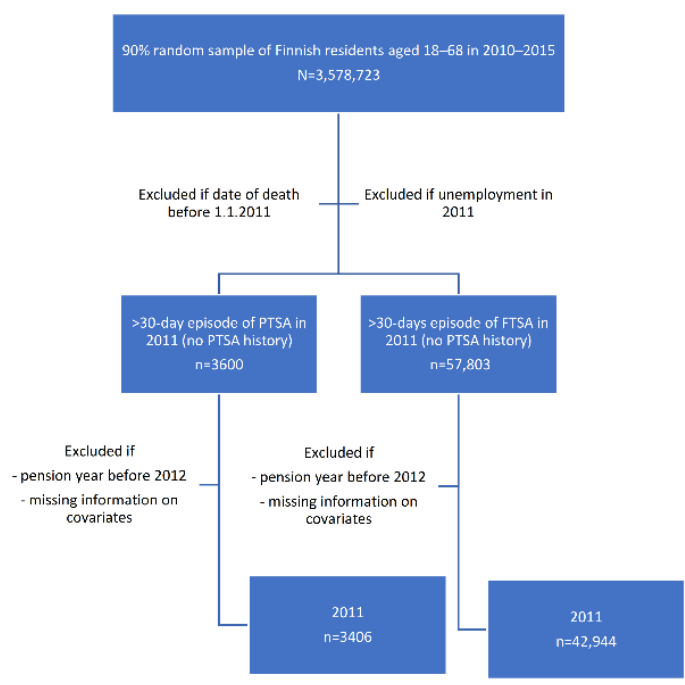

Labour market outcomes: All-cause full-time sickness absence, vocational rehabilitation days per year (2007-2015), unemployment days per year (2012-2015):

\begin{tabular}{lllllllll}
2007 & 2008 & 2009 & 2010 & 2011 & 2012 & 2013 & 2014 & 2015 \\
\hline---- Before index event year & --- & Index event year & --- After index event year & ------
\end{tabular}

Figure 1. Flow chart of participant selection and observational periods. PTSA=part-time sickness absence; FTSA=full-time sickness absence. 


\section{Measures}

The labour market outcomes of interest were: 1) FTSA, 2) vocational rehabilitation, and 3) unemployment. Outcomes were defined as annual days in each of these labour market statuses from January 1, 2007, through December 31, 2015, except for unemployment, where the follow-up was restricted to 1.1.2012-31.12.2015. Records for days of FTSA, vocational rehabilitation and unemployment were obtained from a register of non-salaried periods (the Finnish Centre for Pensions). The registers of the Finnish Centre for Pensions include data on sickness absence and other benefits paid to the employee (not to employer). Records of sickness absence do not include the first 10 days of sickness, as they are covered by the employer and thus not registered by pension insurers. Depending on the collective agreements, longer episodes (even up to 3 months) of sickness absence may also be covered by the employer, and hence are not registered by the Finnish Centre for Pensions. The longer the sickness absence episode, the more likely it is registered. Thus, we decided to focus on episodes lasting at least 30 days.

Days of FTSA and unemployment can be overlapping, as FTSA benefit can be granted to unemployed. The purpose of vocational rehabilitation is to prevent or postpone disability pension and to ensure that workers stay in the workforce for as long as possible, despite illnesses, handicaps or injuries. It is arranged and paid by the earnings-related pension insurers. Measures of rehabilitation include guidance, investigations, work try-outs, work training, education, subsidies for starting or carrying on a business, and various individual solutions to make working easier. ${ }^{19}$

Sociodemographic covariates, all measured at the event year (2011), were sex (men/women), age, and education. Education was classified into: 1=no secondary education; 3 =upper secondary; 5 =short-cycle tertiary; 6 =bachelor or equivalent; $7=$ =master or equivalent; $8=$ doctoral or equivalent. 


\section{Statistical analysis}

Descriptive information for sociodemographic variables, mortality and pensioning were described separately for the two groups: long-term PTSA and long-term FTSA. These were expressed as number of observations and percentages for categorical variables, and as means with standard deviations for continuous variables. Differences between the two groups were tested using $X^{2}$ tests except for continuous variable age, for which t-test was applied.

We calculated the means of annual FTSA and vocational rehabilitation days for each group during the 9-year observation window. For unemployment, we used 4-year observation window from the event year onward. To examine the annual days of each labour market outcome and to plot the trajectory of each of these statuses in relation to the index event, we calculated unadjusted annual means per year and covariate-adjusted estimated marginal rates of annual days in each labour market status for the 2 groups.

To determine the occurrence of sickness absence and vocational rehabilitation during the four years after relative to four years before the index year, we applied repeated-measures negative binomial regression analyses using the generalized estimating equations (GEE) method with exchangeable correlation structure. Sex, age and education were included as covariates. This method considers the intraindividual correlation between the measurements, and results in rate ratio (RR) estimates of the risk after versus before the index year with $95 \%$ confidence intervals $(\mathrm{CI})$. To examine whether the change in time was different across the two groups, we entered an interaction term 'group $\times$ time' into the model. Time was specified as a class (categorical) variable in the analyses. In addition to RR estimates, the GEE models also produced the covariate-adjusted 
estimated marginal rate (i.e., sickness absence days per 1 person-year). The beta-coefficients were exponentiated to represent the rates (i.e., annual adjusted means).

To express the difference in the shape of trajectories (i.e., slopes) of annual days in different labour market outcome statuses before and after 2011, we calculated the rate ratios (RR) per 4 years within 2007-2010 (before) and 2012-2015 (after). Here, time was specified as a continuous variable.

In sensitivity analysis we tested the robustness of our findings and repeated the analyses after excluding individuals whose PTSA in 2011 did not end by 31.12.2011. This was done to ensure that those with PTSA in 2011 were at risk for FTSA in 2012.

We also repeated the analysis including only participants who were employed every year of the 9-year follow-up between 2007 and 2015 (all participants who had a break in work career during the 9 years due to unemployment, a gap between jobs, education, homemaking, or any other reason were excluded). As our two study groups had PTSA or FTSA during the follow-up, it is likely that they also had more work non-participation than observed in the general population during the same time. ${ }^{2021}$ We determined the rate of sickness absence during the four years after relative to four years before the index event within individuals with employment for at least 1 day per year and calculated the annual estimated marginal rate with repeated-measured negative binomial regression analyses using the GEE method with exchangeable correlation structure and logarithm function of annual employment days as offset-variable. This was done to account for time at-risk for sickness absence.

All analyses were performed using SAS statistical software, version 9.4 (SAS Institute, Cary, NC). 
The descriptive statistics for individuals in the two groups are presented in Table 1. Those with longterm PTSA were more often women and they were older than those with long-term FTSA. Participants with PTSA also had higher level of education than those with FTSA. Retirement, morbidity, and mortality rates were highest among individuals with FTSA: a total of $18 \%$ of the FTSA group retired on health grounds during 2012-2015, whereas the corresponding percentage was 10 $\%$ for the PTSA group.

Table 1. Descriptive statistics for individuals with part-time or full-time sickness absence longer than 30 days in 2011.

\begin{tabular}{|c|c|c|c|}
\hline & $\begin{array}{l}\text { First episode of } \\
\text { PTSA* in } 2011\end{array}$ & $\begin{array}{l}\text { Episode of } \\
\text { FTSA }^{* *} \text { in } \\
2011\end{array}$ & P for difference \\
\hline & $n=3406$ & $\mathrm{n}=42944$ & \\
\hline Men, n (\%) & $821(24)$ & 21255 (49) & \\
\hline Women, n (\%) & $2585(76)$ & $21689(51)$ & $<0.001$ \\
\hline Mean age (SD) & $46.6(9.7)$ & $45.0(12.2)$ & $<0.001$ \\
\hline No secondary education & $401(12)$ & $9558(22)$ & \\
\hline Secondary education, $\mathrm{n}(\%)$ & $1656(49)$ & $23838(56)$ & \\
\hline Tertiary, short-cycle, n (\%) & $658(19)$ & $47391(11)$ & \\
\hline Bachelor's degree or equivalent, $\mathrm{n}(\%)$ & $373(11)$ & $2870(7)$ & \\
\hline Master's degree or equivalent, $\mathrm{n}(\%)$ & $285(8)$ & $1748(4)$ & \\
\hline Doctoral degree or equivalent, $\mathrm{n}(\%)$ & $33(1)$ & $139(0.3)$ & $<0.001$ \\
\hline Mean days of sickness absence in 2011 (SD) & $49.1(61.6)$ & $99.7(73.5)$ & $<0.001$ \\
\hline Mortality during $2012-2015, \%$ & $65(2)$ & $1521(4)$ & $<0.001$ \\
\hline Old-age pension during $2012-2015, \%$ & $258(8)$ & $5030(12)$ & $<0.001$ \\
\hline $\begin{array}{l}\text { Full-time work disability pension during 2012- } \\
2015, \%\end{array}$ & $350(10)$ & $7576(18)$ & $<0.001$ \\
\hline
\end{tabular}


Figure 2 shows the observed (unadjusted) and covariate-adjusted trends in mean annual days of FTSA, vocational rehabilitation, and unemployment in the two groups. Table 2 shows the corresponding RRs when contrasting years 2012-2015 to years 2007-2010, and the p-values for interaction term 'group $\times$ time' indicating a difference in the average levels between groups. Table 3 shows the RR estimates regarding the shape of the slope before (2007-2010) and after (2012-2015) 2011.

Table 2. Ratio of annual days per person in sickness absence and vocational rehabilitation in 20122015 versus 2007-2010 in groups of individuals who had long-term PTSA or long-term FTSA in 2011. Years 1, 2, 3, 4 after the long-term sickness absence are contrasted to years $-4,-3,-2$, and -1 before the long-term sickness absence. Year 0 is year 2011 (washout-year). Models are adjusted for sex, age, and education.

\begin{tabular}{|c|c|c|c|c|c|}
\hline & \multicolumn{2}{|c|}{$\begin{array}{l}\text { First episode of PTSA* in } \\
2011\end{array}$} & \multicolumn{2}{|c|}{$\begin{array}{l}\text { Episode of FTSA** in } \\
2011\end{array}$} & \multirow{2}{*}{$\begin{array}{l}\text { Group*time } \\
\text { interaction } \\
\text { P value }\end{array}$} \\
\hline & $\mathrm{RR}$ & $95 \% \mathrm{Cl}$ & $\mathrm{RR}$ & $95 \% \mathrm{Cl}$ & \\
\hline \multicolumn{6}{|l|}{ Sickness absence } \\
\hline $2007-2010$ & 1 & (ref) & 1 & (ref) & \\
\hline $2012-2015$ & 1.94 & $1.75-2.15$ & 1.83 & $1.78-1.88$ & $<0.001$ \\
\hline \multicolumn{6}{|l|}{$\begin{array}{l}\text { Vocational } \\
\text { rehabilitation }\end{array}$} \\
\hline $2007-2010$ & 1 & (ref) & 1 & (ref) & \\
\hline $2012-2015$ & 7.02 & $5.42-9.08$ & 5.96 & $5.34-6.66$ & 0.22 \\
\hline
\end{tabular}

* $>30$-day episode of part-time sickness absence

**> 30-day episode of full-time sickness absence

Annual days of FTSA strongly increased before the index year in both PTSA and FTSA groups (Figure 2 Panel A, Table 3). The level of sickness absence after the onset of long-term PTSA was 1.94 times higher ( $95 \% \mathrm{Cl}$ 1.75-2.15) compared to the level before (Table 2). The corresponding 
rate ratio was 1.83 (95\% $\mathrm{Cl} 1.78-1.88)$ in the FTSA group. A year after the index event year, in 2012, the absolute level of sickness absence was higher among those with long-term FTSA in 2011 compared to those with long-term PTSA in 2011. However, the difference between the two groups diluted during 2013-2015 (Figure 2 Panel A).

We repeated the analysis after excluding individuals whose PTSA did not end by the end of $2011(n=587,17 \%)$. The results for trend and risk of FTSA remained similar to those from the main analysis (Table S1, Figure S1). We also repeated the analyses after excluding participants with any interruptions in employment during 2007-2015. This exclusion omitted $64 \%$ of participants, including those (32\%) who left the labour market during 2012-2015 due to full-time disability pension, old-age pension, or death. The remaining $32 \%$ were people in parental leave, in education, military, or unemployed. In the population with no interruptions in employment, the effect of PTSA was stronger. While days spent on sickness absence increased strongly towards PTSA as well as FTSA, the risk of sickness absence after PTSA was less pronounced ( $R R=1.51,95 \% \mathrm{Cl} 1.08-2.11)$ than the risk of sickness absence after FTSA $(\mathrm{RR}=1.76,95 \% \mathrm{Cl} 1.47-2.10 ; \mathrm{p}$ for group $\times$ time interaction $=$ 0.045) (Table S2). After the index event year, the slope was decreasing for those on PTSA, but for those with FTSA, the level remained high one year after the event year decreasing thereafter. However, a those with FTSA had more sickness absence than those with PTSA during the entire follow-up (Figure S2).

The ratio of annual days in vocational rehabilitation was substantially higher after both PTSA ( $R R=7.02,95 \% \mathrm{Cl} 5.42-9.08$ ) and FTSA ( $R R=5.96,95 \% \mathrm{Cl} 5.34-6.66)$ compared to before (Table 2). However, the slope of annual days in rehabilitation was steady after the onset of PTSA $\left(R_{4 y \text { years post event }}=0.88,95 \% \mathrm{Cl} 0.60-1.27\right)$, and decreasing after the onset of FTSA (RR 4years post event $_{\text {a }}=0.51$, 95\% $\mathrm{Cl}$ 0.44-0.58) (Table 3). The absolute level of vocational rehabilitation was broadly similar among those with PTSA and FTSA after 2011 (Figure 2, Panel B). 
Table 3. Trends of sickness absence, vocational rehabilitation, and unemployment within two time periods: 2007-2010 and 2012-2015. Models are adjusted for sex, age, and education.

\begin{tabular}{cllll}
\hline & \multicolumn{2}{l}{ First episode (>30 days) of PTSA in 2011 } & \multicolumn{2}{l}{$>$ 30 days episode of FTSA in 2011 } \\
\hline Sickness absence & RR4years & $95 \% \mathrm{Cl}$ & RR4years & $95 \% \mathrm{Cl}$ \\
\hline $2007-2010$ & 9.23 & $6.77-12.6$ & 4.43 & $4.14-4.74$ \\
\hline $2012-2015$ & 0.88 & $0.70-1.09$ & 0.41 & $0.39-0.44$ \\
\hline Vocational rehabilitation & & & \\
\hline $2007-2010$ & 1.35 & $0.66-2.77$ & 1.47 & $1.12-1.93$ \\
\hline $2012-2015$ & 0.88 & $0.60-1.27$ & 0.51 & $0.44-0.58$ \\
\hline Unemployment & & & & \\
\hline $2012-2015$ & 5.77 & $4.67-7.14$ & 3.26 & $3.12-3.40$ \\
\hline
\end{tabular}

In relation to days of unemployment (PTSA is not granted for unemployed), we restricted the study populations to those without any unemployment in 2011 and followed up their unemployment from 2012 onwards. Annual days unemployed increased throughout the four-year follow-up period in all groups. In relative terms the increase during the years after versus before in those with PTSA ( $R R=5.77,95 \% \mathrm{Cl}$ 4.67-7.14) was higher than that in FTSA group ( $R R=3.26,95 \% \mathrm{Cl}$ 3.12-3.40) (Table 3). The absolute level of unemployment during 2012-2015 was lower in the PTSA group than in the FTSA group (Figure 2 Panel C). 


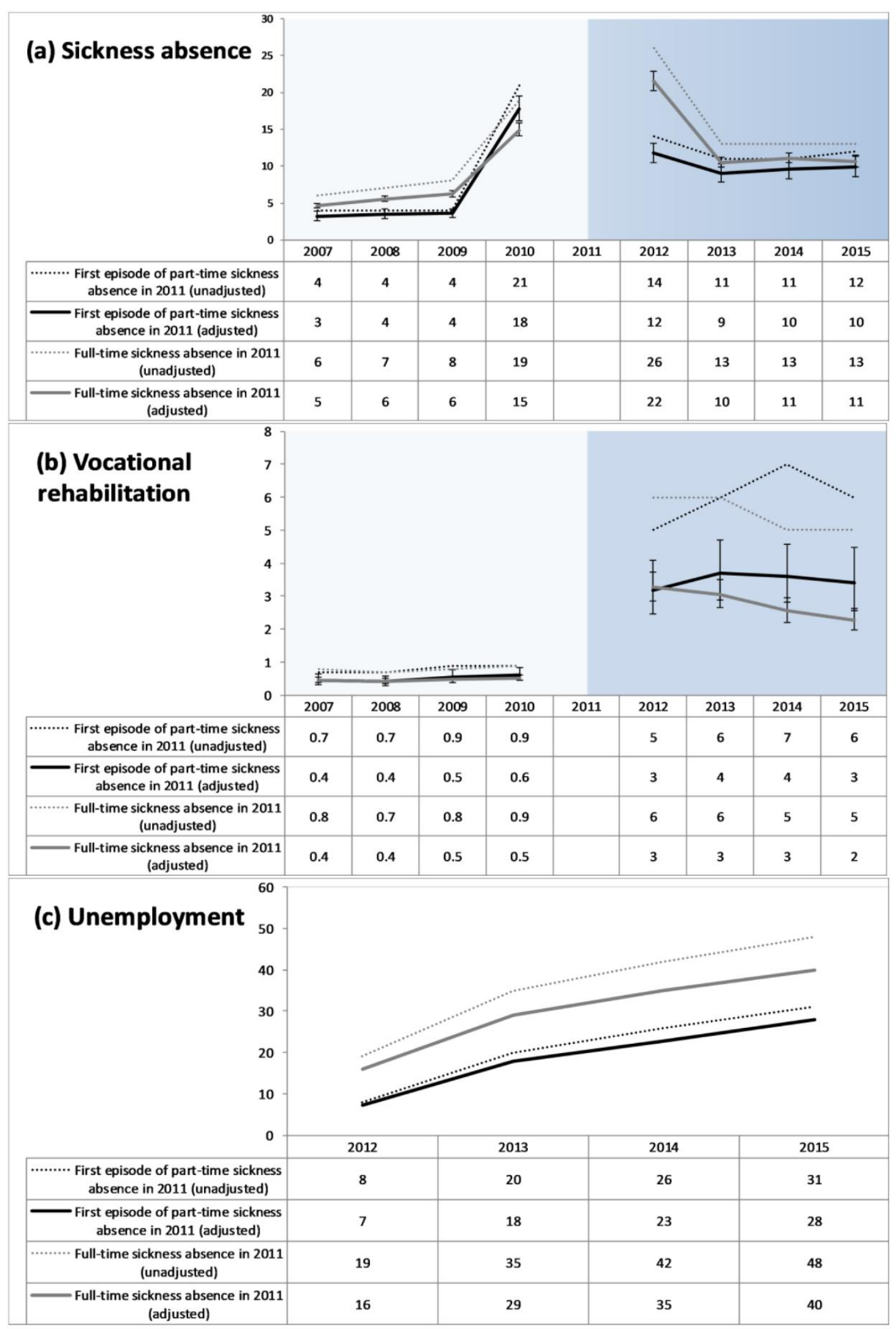

Figure 2. Mean annual number of days spent (a) in full-time sickness absence, (b) at vocational rehabilitation during 2007-2015, and (c) unemployed during 2012-2015 in those with >30-days PTSA or FTSA starting in 2011. 


\section{DISCUSSION}

In this study of working population in Finland, we used nationwide register data with repeated measures of annual days in different labour market groups to determine labour market participation before and after the onset of long-term PTSA compared to long-term FTSA. We found that long-term PTSA marked a decline in labour market participation. In absolute terms, this decline was smaller than that in employees with long-term FTSA. To our knowledge, this is the first longitudinal study with long before-after observation periods on the associations of long-term part-time sickness absence with labour market participation.

FTSA increased considerably during the last year before the onset of long-term PTSA. This was expected, as many people transfer from FTSA to PTSA. Previous studies compared PTSA to FTSA and suggested that return to work may be faster after PTSA than FTSA. ${ }^{8-101322}$ Our results support this possibility, as the number of days on FTSA was higher one year after the index year among those on long-term FTSA than among those on long-term PTSA. Similarly, the rate of retirement due to health grounds after the long-term FTSA was twice that after long-term PTSA. The elevated levels of annual sickness absence days one year after the index year declined in the following years in PTSA and FTSA groups and were broadly at the same level during follow-up years 2 to 4 in these groups.

In sensitivity analysis, we included only those individuals who were employed during the entire follow-up, i.e., those who were able to maintain their work and ability to work. We observed a better prognosis for labour market participation for employees on PTSA than for those on FTSA. Overall, these findings suggest that those with long-term PTSA had better ability to work prior to the index year, and they were able to maintain their work and ability to work after the index year better compared to those with long-term FTSA. As PTSA is prescribed to those partially able to 
work, it is not surprising to find that they have less sickness absence after the index event year than those with FTSA.

PTSA is voluntary for the employee and the employer, and at the time of this study this absence mode was not widely used in Finland. The choice to use PTSA instead of FTSA needs to be agreed by the employer, employee, and occupational physician, and the required modifications to work to allow part-time working may not be possible in all jobs. In this study, the group of participants with PTSA included a higher proportion of women and those with higher education than the group of participants with FTSA, suggesting selection to PTSA according to sex and education. We were able to control analyses for both these factors but not for other factors potentially affecting sickness absence mode and labour market participation in this study. For example, it may be important to consider selection regarding working capacity when comparing the outcomes. Furthermore, we had no information about sickness absence diagnoses.

A novel feature of our study design was the follow-up of the outcomes both before and after the index year. This allowed a comparison of trends in labour market outcomes between these two periods. We found that the relative risk of sickness absence and the likelihood of participating in vocational rehabilitation were higher after than before long-term PTSA. This finding is plausible and consistent with other research. In the Finnish social security system, a person can have sickness absence benefits for a maximum of one year. If the ability to work has not recovered after that, vocational rehabilitation needs to be prioritized before disability pension. Vocational rehabilitation aims to prevent or postpone disability pension. ${ }^{19}$ Recently, two Finnish populationbased cohort studies on vocational rehabilitation were conducted, ${ }^{2324}$ with the first finding that $36 \%$ of those who received vocational rehabilitation in $2008-2010$ had relatively high work participation both before and after vocational rehabilitation. ${ }^{23}$ However, $39 \%$ did not regain full ability to work after vocational rehabilitation, ${ }^{23}$ and according to the other study the overall effectiveness of vocational rehabilitation was modest. ${ }^{24} \mathrm{~A}$ study conducted in the US found no evidence that 
increasing levels of physical therapy improved workers' compensation outcomes or return to work. ${ }^{25}$ Our results showed little difference in vocational rehabilitation frequency between those on PTSA or FTSA after the index event.

In our study, the absolute level of unemployment was lower in the long-term PTSA group than in the long-term FTSA group. This confirms an earlier study suggesting that unemployment is more common among employees with FTSA than among those with PTSA, ${ }^{26}$ possibly due to the adverse effect of work disability on retaining sustainable employment (the poorer the ability to work, the more elevated the unemployment trajectory). However, there was a slightly steeper slope for future unemployment in the PTSA compared to the FTSA group. One explanation may be that those receiving PTSA do not qualify for a full-time disability pension as frequently as those receiving FTSA. Rejected disability pension often lead to a path of unemployment. ${ }^{21}$

The strengths of this study were the large population-based cohort data from a reliable national register. We were able to follow up different labour market outcomes across a nineyear period centred on the first onset of PTSA. We were also able to censor participants at death, full-time disability pension and old-age pension year and minimize any loss to follow-up.

Register-based approaches include some inherent limitations. The analyses were controlled for known sociodemographic risk factors for work disability and unemployment, such as female sex, older age and low education, but we had no data on other important predictors, such as self-rated health, chronic illnesses, sleep problems, body mass index, smoking, or work-related exposures. ${ }^{2728}$ Although education level may serve as a proxy variable for physical and ergonomic exposures, residual confounding due to unmeasured covariates is possible. Moreover, this is an observational study precluding any conclusions regarding causality. Sickness absence data were from the Finnish Centre for Pensions registers, which do not include short-term episodes of illness 
covered by the employer. Thus, the results of our study involve long-term sickness absence episodes only.

Knowledge about the labour market outcomes and trajectories among people with reduced ability to work may benefit employers and policymakers providing insights into potential effectiveness of employers' and pension insurance institutions' efforts to increase labour market participation. Our results are consistent with the notion that attempts to transfer individuals from FTSA to PTSA, when possible, might support increased labour force participation. 


\section{REFERENCES}

1 ILO code of practice. Managing disability in the workplace., Geneva: International Labor Organization 2002.

2 Loo R. Attitudes Toward Employing Persons With Disabilities: A Test of the SympathyDiscomfort Categories. J App/ Soc Psychol 2004;34:2200-2214.

3 Yelin EH, L. T. Disability and the characteristics of employment Monthly Labor Review: United States Department of Labor, Bureau of Labor Statistics 2003;20-31.

https://www.bls.gov/opub/mlr/2003/05/art3full.pdf.

4 Table 1. Employment status of the civilian noninstitutional population by disability status and selected characteristics, 2015 annual averages: United States Department of Labor, Bureau of Labor Statistics 2016. https://www.bls.gov/news.release/disabl.t01.htm.

5 Kausto J, Miranda H, Martimo KP, Viikari-Juntura E. Partial sick leave--review of its use, effects and feasibility in the Nordic countries. Scand J Work Environ Health 2008;34:239-49.

6 Dorrington S, Roberts E, Mykletun A, Hatch S, Madan I, Hotopf M. Systematic review of fit note use for workers in the UK. Occup Environ Med 2018;75:530-539.

7 Viikari-Juntura E, Virta $\mathrm{L}$, Kausto $\mathrm{J}$ et al. Legislative change enabling use of early part-time sick leave enhanced return to work and work participation in Finland. Scand J Work Environ Health 2017;43:447-456.

8 Kausto J, Viikari-Juntura E, Virta L, Gould R, Koskinen A, Solovieva S. Effectiveness of new legislation on partial sickness benefit on work participation: a quasi-experiment in Finland. BMJ Open 2014;4:e006685.

9 Andren D. Does part-time sick leave help individuals with mental disorders recover lost work capacity? J Occup Rehabil 2014;24:344-60.

10 Andren D, Svensson M. Part-time sick leave as a treatment method for individuals with musculoskeletal disorders. J Occup Rehabil 2012;22:418-26.

11 Bethge M. Effects of graded return-to-work: a propensity-score-matched analysis. Scand J Work Environ Health 2016;42:273-9.

12 Shiri R, Kausto J, Martimo KP, Kaila-Kangas L, Takala EP, Viikari-Juntura E. Health-related effects of early part-time sick leave due to musculoskeletal disorders: a randomized controlled trial. Scand J Work Environ Health 2013;39:37-45.

13 Viikari-Juntura E, Kausto J, Shiri R et al. Return to work after early part-time sick leave due to musculoskeletal disorders: a randomized controlled trial. Scand J Work Environ Health 2012;38:134-43.

14 Kausto J, Solovieva S, Virta L, Viikari-Juntura E. Partial sick leave associated with disability pension: propensity score approach in a register-based cohort study. BMJ Open 2012;2.

15 Streibelt M, Burger W, Nieuwenhuijsen K, Bethge M. Effectiveness of Graded Return to Work After Multimodal Rehabilitation in Patients with Mental Disorders: A Propensity Score Analysis. J Occup Rehabil 2018;28:180-189.

16 Rehwald K, Rosholm M, Rouland B. Labour market effects of activating sick-listed workers. Labour Economics 2018;53:15-32.

17 Partial sickness allowance: Kela (Social Insurarance Institution of Finland) 2014. https://www.kela.fi/web/en/partial-sickness-allowance?inheritRedirect=true. 07/12/2018

18 Remote access use (Fiona): Statistics Finland. https://www.stat.fi/tup/mikroaineistot/etakaytto en.html.

19 Rehabilitation: Finnish Centre for Pensions 2019. https://www.etk.fi/en/statistics2/statistics/rehabilitation/\#toggle-id-2. 
20 Virtanen M, Kivimaki M, Vahtera J et al. Sickness absence as a risk factor for job termination, unemployment, and disability pension among temporary and permanent employees. Occup Environ Med 2006;63:212-7.

21 Perhoniemi R, Blomgren J, Laaksonen M. Sources of income following a rejected disability pension application: a sequence analysis study. Disabil Rehabil 2019:1-9.

22 Hogelund J, Holm A, McIntosh J. Does graded return-to-work improve sick-listed workers' chance of returning to regular working hours? J Health Econ 2010;29:158-69.

23 Leinonen $T$, Solovieva S, Husgafvel-Pursiainen K, Laaksonen M, Viikari-Juntura E. Do individual and work-related factors differentiate work participation trajectories before and after vocational rehabilitation? PLoS One 2019;14:e0212498.

24 Leinonen T, Viikari-Juntura E, Husgafvel-Pursiainen K, Juvonen-Posti P, Laaksonen M, Solovieva S. The effectiveness of vocational rehabilitation on work participation: a propensity score matched analysis using nationwide register data. Scand J Work Environ Health 2019.

25 Leung N, Tao XG, Bernacki EJ. The Relationship of the Amount of Physical Therapy to Time Lost From Work and Costs in the Workers' Compensation System. Journal of Occupational and Environmental Medicine 2019;61:635-640.

26 Viikari-Juntura E, Leinonen T, Virta LJ et al. Early part-time sick leave results in considerable savings in social security costs at national level: an analysis based on a quasi-experiment in Finland. Scand J Work Environ Health 2019;45:203-208.

27 Airaksinen J, Jokela $\mathrm{M}$, Virtanen $\mathrm{M}$ et al. Prediction of long-term absence due to sickness in employees: development and validation of a multifactorial risk score in two cohort studies. Scand J Work Environ Health 2018.

28 Airaksinen J, Jokela M, Virtanen $\mathrm{M}$ et al. Development and validation of a risk prediction model for work disability: multicohort study. Sci Rep 2017;7:13578. 


\section{SUPPLEMENTARY MATERIAL}

Table S1. Ratio of annual days per person in sickness absence in 2012-2015 versus 2007-2010 in individuals who had their first episode of $>30$-day part-time sickness absence (PTSA) and whose PTSA ended during 2011 or >30-day fulltime sickness absence (FTSA) episode in 2011. Years 1, 2, 3, 4 after the PTSA are contrasted to years $-4,-3,-2$, and -1 before the PTSA. Year 0 is year 2011 (washout-year). Models are adjusted for sex, age, and education.

\begin{tabular}{|c|c|c|c|c|c|c|}
\hline & & \multicolumn{2}{|c|}{$\begin{array}{l}\text { First episode (>30 } \\
\text { days) of PTSA in } 2011\end{array}$} & \multicolumn{2}{|c|}{$\begin{array}{l}>30 \text { days episode } \\
\text { of FTSA in } 2011\end{array}$} & \multirow{2}{*}{$\begin{array}{l}\text { Cohort*time } \\
\text { interaction } \\
\text { P-value }\end{array}$} \\
\hline & & $\mathrm{RR}$ & $95 \% \mathrm{Cl}$ & $\mathrm{RR}$ & $95 \% \mathrm{Cl}$ & \\
\hline \multicolumn{7}{|l|}{ FTSA } \\
\hline & 2007-2010 & 1 & & 1 & & \\
\hline & $2012-2015$ & 1.84 & $1.65-2.06$ & 1.83 & $\begin{array}{l}1.78- \\
1.88\end{array}$ & $<0.001$ \\
\hline
\end{tabular}

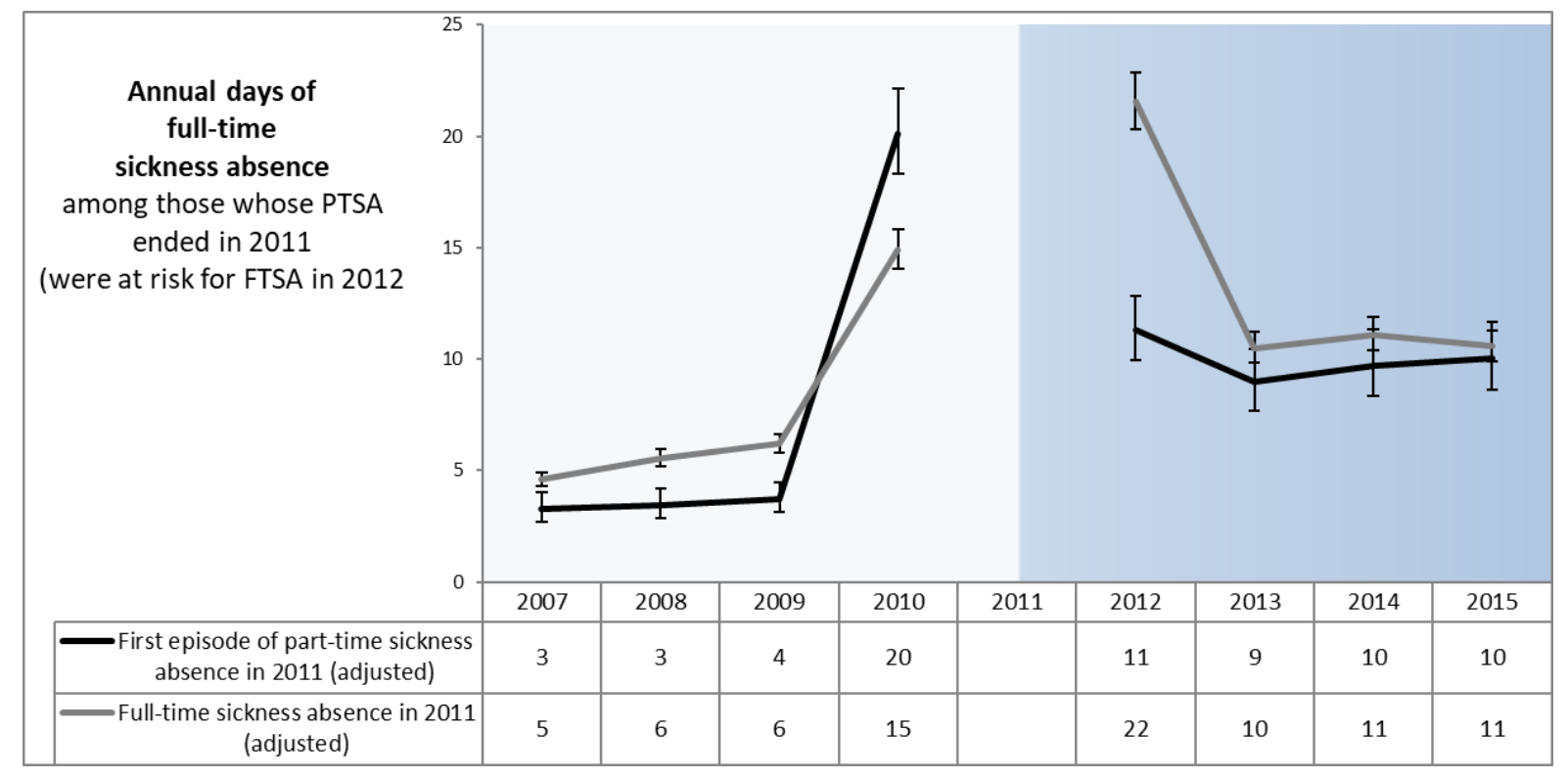

Figure S1. Sex-, age- and education-adjusted mean (and 95\% $\mathrm{Cl}$ ) annual number of days spent in fulltime sickness absence (FTSA during 2007-2010 and 2012-2015 in those with part-time sickness absence episode which ended in 2011 and full-time sickness absence in 2011. 
Table S2. Ratio of annual days per person in sickness absence in 2012-2015 versus 2007-2010 in individuals who had their first episode of $>30$-day part-time sickness absence (PTSA) or >30-day fulltime sickness absence (FTSA) episode in 2011 and who were in employment in each year over the 9 year observation window (36\% of the participants). Years 1, 2, 3, 4 after the PTSA are contrasted to years $-4,-3,-2$, and -1 before the PTSA. Year 0 is year 2011 (washout-year). Models are adjusted for sex, age, and education.

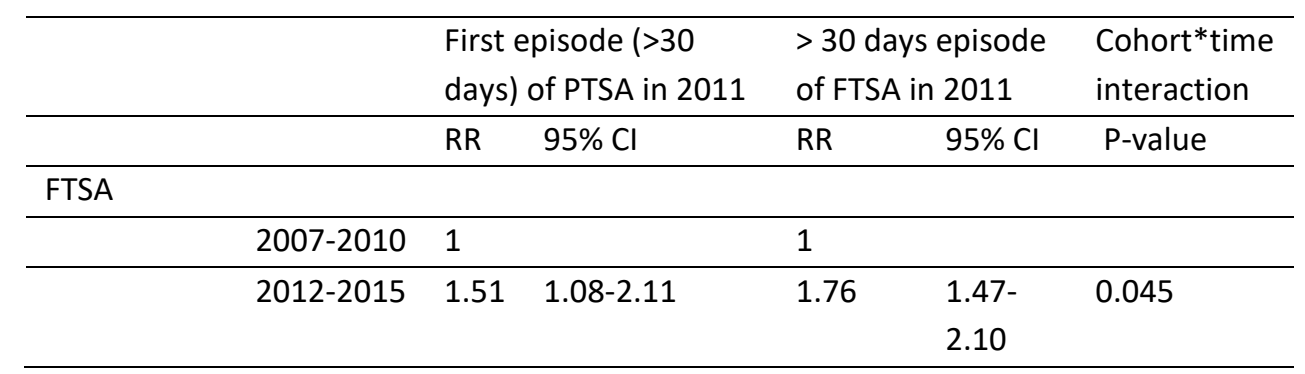

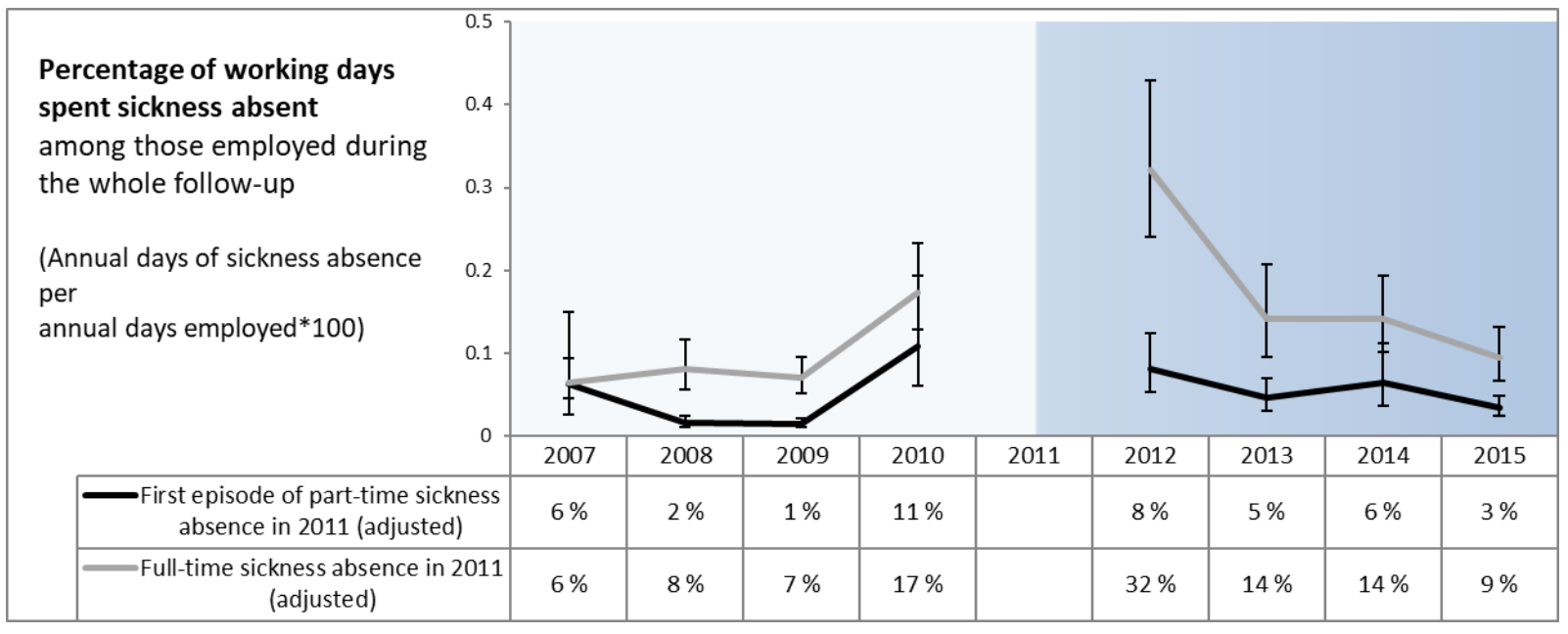

Figure S2. Percentage of working days spent sickness absent among those employed during the follow-up. Sex-, age- and education-adjusted mean (and $95 \% \mathrm{Cl}$ ) annual number of days spent in sickness absence per days in employment during 2007-2010 and 2012-2015 in those with part-time and full-time sickness absence in 2011. 